\title{
RANCANG BANGUN BLADE TURBIN ANGIN TIPE HORIZONTAL
}

\author{
Rusuminto Syahyuniar ${ }^{1}$, Yuliana Ningsih ${ }^{2}$, Herianto $^{3}$ \\ ${ }^{1,2)}$ Staf Pengajar Mesin Otomotif Politeknik Negeri Tanah Laut \\ 3) Mahasiswa Jurusan Mesin Otomotif \\ 1) Email : rusumintosyahyuniar@politala.ac.id
}

Naskah diterima: 18 Mei 2018 ; Naskah disetujui: 24 Juni 2018

\begin{abstract}
ABSTRAK
Turbin angin adalah kincir angin yang digunakan untuk membangkitkan tenaga listrik. Di dalam turbin angin terdapat komponen yang sangat penting yaitu blade/baling-baling. Blade merupakan bagian dari turbin angin yang berfungsi menerima energi kinetik dari angin dan merubahnya menjadi energi gerak (mekanik) putar pada poros penggerak, dari fungsi blade tersebut dan beberapa faktor di atas maka dilakukan eksperimen lebih lanjut untuk mencoba membuat blade turbin angin horizontal. Tujuan dari penelitian ini adalah untuk mengetahui cara perancangan pembuatan blade turbin angin tipe horizontal, dan mengetahui cara pembuatan blade turbin tipe horizontal. Pada saat perancangan blade tersebut diperlukan perancangan gambar teknik geometris tampak depan, tampak atas, dan tampak samping agar menghasilkan tangkapan angin yang baik dan putaran poros yang optimal. Adapun perancangan dan pembuatan blade adalah dengan pembentukan blade, pembuatan penampang blade, pengeleman, dan pemasangan blade ke poros, dan pengujian. Dari pengujian kecepatan poros tersebut maka didapatkan hasil kecepatan putaran poros dalam 10 kali pengujian yang paling maksimal adalah $171 \mathrm{rpm}$, dengan kecepatan angin $18 \mathrm{~m} / \mathrm{s}$.
\end{abstract}

Kata Kunci : Blade, Kecepatan Poros, Perancangan dan Pembuatan Blade

\section{PENDAHULUAN}

Sudu adalah baling-baling pada turbin angin. Sudu pada turbin angin biasanya dihubungkan dengan rotor pada turbin angin.Sudu merupakan salah satu bagian dari turbin angin yang memiliki fungsi menerima energi kinetik dari angin dan merubahnya menjadi energi gerak (mekanik) putar pada poros penggerak, angin yang menghembus menyebabkan turbin tersebut berputar. Pada sebuah turbin angin, baling-baling rotor dapat berjumlah 3 atau lebih.

Turbin angin sumbu horizontal jenis ini ialah jenis turbin angin yang paling banyak digunakan sekarang. Turbin ini terdiri dari sebuah menara yang di puncaknya terdapat sebuah baling-baling yang berfungsi sebagai rotor dan menghadap atau membelakangi arah angin. Sebagian besar turbin angin jenis ini yang dibuat sekarang mempunyai dua atau tiga bilah baling-baling walaupun ada juga turbin bilah dengan baling-baling kurang atau lebih daripada yang disebut diatas.

Biasanya turbin jenis ini memiliki sudu berbentuk airfoil seperti bentuk sayap pada pesawat. Pada turbin ini, putaran rotor terjadi karena adanya gaya angkat (lift) pada sudu yang ditimbulkan oleh aliran angin. Pada tipe Horizontal memanfaatkan efek gaya angkat sebagai gaya penggerak rotor. Oleh karena itu kecepatan linier sudu dapat lebih besar daripada kecepatan angin. Turbin ini cocok digunakan pada tipe angin sedang dan tinggi, dan banyak digunakan sebagai pembangkit listrik skala besar.

Dari fungsi blade tersebut dan beberapa faktor di atas maka penulis tertarik melakukan eksperimen lebih lanjut untuk mencoba membuat blade turbin angin horizontal, sehingga saya mengambil judul "Rancang Bangun blade Turbin Angin Horizontal"

\section{TINJAUAN PUSTAKA}

\section{Turbin Angin}

Turbin angin adalah kincir angin yang digunakan untuk membangkitkan tenaga listrik. Turbin angin ini pada awalnya dibuat untuk mengakomodasi kebutuhan para petani dalam melakukan penggilingan padi, keperluan irigasi, dan lain-lain. Turbin angin terdahulu banyak dibangun di Denmark, Belanda serta negaranegara Eropa lainnya dan lebih dikenal dengan istilah windmill. 
Kini turbin angin lebih banyak digunakan untuk mengakomodasi kebutuhan listrik masyarakat, dengan menggunakan prinsip konversi energi dan menggunakan sumber daya alam yang dapat diperbaharui yaitu angin. Walaupun sampai saat ini pembangunan turbin angin masih belum dapat menyaingi pembangkit listrik konvensional (Contoh: PLTD, PLTU, dan lain-lain), turbin masih lebih dikembangkan oleh para ilmuan karena dalam waktu dekat manusia akan dihadapkan dengan masalah kekurangan sumber daya alam tak dapat diperbaharui (Contoh: batubara, minyak bumi) sebagai bahan dasar untuk membangkitkan listrik (Soroyo,2001:12).

\section{Jenis-jenis tubin angin}

\section{Turbin Angin Sumbu Horizontal}

Turbin angin jenis ini ialah jenis turbin angin yang paling banyak digunakan sekarang. Turbin ini terdiri dari sebuah menara yang di puncaknya terdapat sebuah baling-baling yang berfungsi sebagai rotor dan menghadap atau membelakangi arah angin. Sebagian besar turbin angin jenis ini yang dibuat sekarang mempunyai dua atau tiga bilah baling-baling.

Biasanya turbin jenis ini memiliki sudu berbentuk airfoil seperti bentuk sayap pada pesawat. Pada turbin ini, putaran rotor terjadi karena adanya gaya angkat (lift) pada sudu yang ditimbulkan oleh aliran angin. Pada tipe HAWT memanfaatkan efek gaya angkat sebagai gaya penggerak rotor. Oleh karena itu kecepatan linier sudu dapat lebih besar daripada kecepatan angin. Turbin ini cocok digunakan pada tipe angin sedang dan tinggi, dan banyak digunakan sebagai pembangkit listrik skala besar (Sumiati Ruzita, 2014:).

a Kelebihan Turbin Angin Sumbu Horizontal (TASH)

1. Dasar menara yang tinggi membolehkan akses ke angin yang lebih kuat di tempat-tempat yang memiliki geseran angin (perbedaan antara laju dan arah angin antara dua titik yang jaraknya relatif dekat di dalam atmosfer bumi di sejumlah lokasi geseran angin.

2. Setiap sepuluh meter ke atas, kecepatan angin meningkat sebesar $20 \%$.

3. Efisiensi lebih tinggi, karena blades selalu bergerak tegak lurus terhadap arah angin, dan menerima daya sepanjang putaran.

b. Kelemahan Turbin Angin Sumbu Horizontal (TASH)

1. Menara yang tinggi serta bilah yang panjang sulit diangkut, diperkirakan besar biaya transportasi bisa mencapai $20 \%$ dari seluruh biaya peralatan turbin angin.
2. Konstruksi menara yang besar dibutuhkan untuk menyangga bilah-bilah yang berat, gearbox, dan generator (Gatot Suwoto, 2001:6).

\section{Turbin Angin Sumbu Vertikal}

Turbin angin sumbu vertikal/tegak (atau TASV) memiliki poros/sumbu rotor utama yang disusun tegak lurus. Kelebihan utama susunan ini adalah turbin tidak harus diarahkan ke angin agar menjadi efektif. Kelebihan ini sangat berguna di tempat-tempat yang arah anginnya sangat bervariasi.

Dengan sumbu yang vertikal, generator serta gearbox bisa ditempatkan di dekat tanah, jadi menara tidak perlu menyokongnya dan lebih mudah diakses untuk keperluan perawatan. Tapi ini menyebabkan sejumlah desain menghasilkan tenaga putaran yang berdenyut. Drag (gaya yang menahan pergerakan sebuah benda padat melalui fluida (zat cair atau gas) bisa saja tercipta saat kincir berputar.

Karena sulit dipasang di atas menara, turbin sumbu tegak sering dipasang lebih dekat ke dasar tempat diletakkan, seperti tanah atau puncak atap sebuah bangunan. Kecepatan angin lebih pelan pada ketinggian yang rendah, sehingga yang tersedia adalah energi angin yang sedikit turbin TASV ini juga mempunyai kelebihan dan kelemahan yaitu:

\section{Kelebihan TASV}

1. Tidak membutuhkan struktur menara yang besar.

2. Karena bilah-bilah rotornya vertikal, tidak dibutuhkan mekanisme yaw.

3. Sebuah TASV bisa diletakkan lebih dekat ke tanah, membuat pemeliharaan bagianbagiannya yang bergerak jadi lebih mudah.

4. Desain TASV berbilah lurus dengan potongan melintang berbentuk kotak atau empat persegi panjang memiliki wilayah tiupan yang lebih besar untuk diameter tertentu daripada wilayah tiupan berbentuk lingkarannya TASH.

5. TASV memiliki kecepatan awal angin yang lebih rendah daripada TASH.

6. TASV bisa didirikan pada lokasi-lokasi dimana struktur yang lebih tinggi dilarang dibangun.

7. TASV yang ditempatkan di dekat tanah bisa mengambil keuntungan dari berbagai lokasi yang menyalurkan angin serta meningkatkan laju angin (seperti gunung atau bukit yang puncaknya datar dan puncak bukit), TASV tidak harus diubah posisinya jika arah angin berubah.

\section{Kelemahan TASV}

1. Kebanyakan TASV memproduksi energi hanya 50\% dari efisiensi TASH karena drag tambahan yang dimilikinya saat kincir berputar. 
2. TASV tidak mengambil keuntungan dari angin yang melaju lebih kencang di elevasi yang lebih tinggi.

3. Kebanyakan TASV mempunyai torsi awal yang rendah, dan membutuhkan energi untuk mulai berputar.

4. Sebuah TASV yang menggunakan kabel untuk menyanggahnya memberi tekanan pada bantalan dasar karena semua berat rotor dibebankan pada bantalan. Kabel yang dikaitkan ke puncak bantalan meningkatkan daya dorong ke bawah saat angin bertiup.

\section{Bagian Bagian Turbin angin}

\section{Transmisi}

Pada umumnya transmisi di turbin angin berfungsi untuk memindahkan daya dari rotor ke generator dengan dipercepat putaranya. Hal ini diperlukan karena umumnya putaran rotor berotasi pada putara rendah, sementara generatornya bekerja pda putaran tinggi.

1. Generator

Generator merupakan komponen terpenting dalam sistem turbin angin, dimana fungsinya adalah merubah energi gerak (mekanik) putar pada poros penggerak menjadi energi listrik.

2. Poros Rotor

Poros rotor berfungsi untuk memindahkan daya dari rotor ke generator, dapat secara langsung maupun melalui mekanisme transmisi gearboks.

\section{Rotor $\mathrm{Hub}$}

Hub merupakan bagian dari rotor yang berfungsi menghubungkan sudu dengan shaft (poros) utama.

4. Sudu (Blade /Baling-baling)

Rotor trubin angin yang terdiri dari balingbaling/sudu dan rotor merupakan bagian dari turbin angin yang berfungsi menerima energi kinetik dari angin dan merubahnya menjadi energi gerak (mekanik) putar pada poros penggerak. Pada sebuah turbin angin, balingbaling rotor dapat berjumlah 1, 2, 3 atau lebih.Bentuk sudu yang digunakan pada turbin angin adalah Horozontal dengan jumlah sudu 3 (Khairul Amri, 2014:14).

\section{Konsep Jumlah Sudu}

Jumlah sudu (blade) pada turbin angin sangat bervariasi dan mempengaruhi setiap kinerja dari turbin angin tersebut. Penggunaan jumlah sudu tergantung dari keadaan lingkungan kerja dari turbin dan penggunaan dari turbin tersebut, misalkan pada daerah kecepatan angin rendah orang biasanya menggunakan turbin angin tiga sudu karena sudu tersebut bisa menangkap energi angin lebih efektif dari jumlah sudu yang sedikit. Hal ini bisa kita simpulkan bahwa jumlah sudu bisa mempengaruhi dari kinerja turbin angin.
1. Konsep satu sudu, sulit setimbang, membutuhkan angin yang sangat kencang untuk menghasilkan gaya angkat memutar, dan menghasilkan noise di ujungnya. Konsep ini telah dikembangkan sukses di Jerman.

2. Konsep dua sudu, mudah untuk setimbang, tetapi kesetimbangannya masih mudah bergeser. Desain sudu harus memiliki kelengkungan yang tajam untuk dapat menangkap energi angin secara efektif, tetapi pada kecepatan angin rendah (sekitar $3 \mathrm{~m} / \mathrm{s}$ ) putarannya sulit dimulai.

3. Konsep tiga sudu, lebih setimbang dan kelengkungan sudu lebih halus untuk dapat menangkap energi angin secara efektif. Konsep ini paling sering dipakai pada turbin komersial.

4. Konsep multi sudu (misalnya 12 sudu), justru memiliki efisiensi rendah, tetapi dapat menghasilkan momen gaya awal yang cukup besar untuk mulai berputar, cocok untuk kecepatan angin rendah walaupun dioperasikan dengan transmisi gear sampai 1:10. Memiliki profil sudu yang tipis, kecil, kelengkungan halus, dan konstruksi yang solid. Konsep ini banyak dijumpai pada turbin angin untuk keperluan memompa air, menggiling biji-bijian, karena murah dan mampu bekerja pada kecepatan angin rendah sehingga tower tidak perlu terlalu tinggi dan air dapat dipompa secara optimal (Harrison, 2000:9).

Bentuk kipas yang akan digunakan dari turbin angin adalah Horizontal.

Luasan kipas dapat dihitung

Solidity $=\frac{B \cdot a}{A}$

Dimana: $B=$ Jumlah sudu

$$
A=\text { Luasan Tangkapan Agin }
$$$$
\alpha=\text { Luasan Blade }
$$

Sedangkan luasan tangkapan angin bisa didapat dengan persamaan:

$$
\begin{gathered}
A=\pi r^{2} \\
\text { Dimana: } \mathrm{r}=\text { jari-jari Blade } \\
\pi=3,14
\end{gathered}
$$

Sedangkan jumlah massa per unit waktu dapat dihitung dengan persamaan:

$$
\begin{aligned}
m=A v \rho & \text { Dimana: } A \\
\text { ) } & =\text { Luas Penampang } \\
v & =\text { Kecepatan Angin }
\end{aligned}
$$
$\left(\mathrm{m}^{2}\right)$

$(\mathrm{m} / \mathrm{s})$

$$
\rho=\operatorname{Kerapatan}\left(\mathrm{kg} / \mathrm{m}^{2}\right)
$$

\section{Energi Angin}

Energi angin merupakan enegi alternatif yang mempunyai prosfek, Karena merupakan sumber energi yang bersih dan terbarukan kembali. Angin adalah udara yang bergerak yang diakibatkan oleh rotasi bumi dan juga karena adanya perbedaan tekanan udara disekitarnya. Angin bergerak dari 
tempat bertekanan udara tinggi ke bertekanan udara rendah. Pemanasan oleh matahari, maka udara memuai. Tekanan udara yang telah memuai masa jenisnya menjadi lebih ringan sehinga naik. Apabila hal ini terjadi, tekanan udara turun. Udara disekitarnya mengalir ketempat yang bertekanan rendah. Udara menyusut menjadi lebih berat dan turun ketanah. Di atas tanah udara menjadi panas lagi dan naik kembali. Aliran naiknya udara panas dan turunnya udara dingin ini dikarenakan konveksi (Daryanto 2007:9).

\section{Karakteristik angin}

Prinsip dasar kerja dari turbin angin adalah mengubah energi mekanis dari angin menjadi energi putar pada kincir, lalu putaran kincir digunakan untuk memutar generator, yang akhirnya akan menghasilkan listrik. (Martono, 2019)

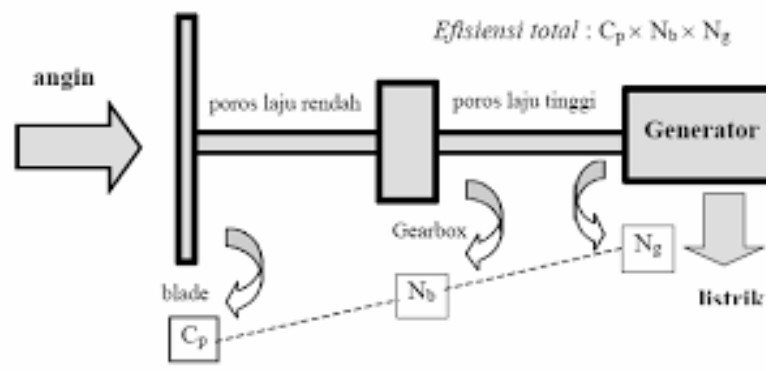

Gambar 1 Prinsip kerja turbin angin (Martono, 2009)

\section{Optimasi Energi angin}

Optimasi dari turbin angin dapat ditinjau dari beberapa faktor yang mempengruhi dari turbin tersebut untuk mendapatkan torsi yang optimum (Firman Aryanto, 2013).
1. Kecepaatan angin
2. Arah kecepatan angin
3. Suhu udara
4. Putaran turbin
5. Sudut sudu
6. Jumlah sudu
7. Putaran alternator
8. Kecepatan putaran turbin
9. Jari-jari turbin angin.

\section{METODOLOGI}

\section{Waktu dan Tempat}

Pengerjaan Tugas Akhir ini dilaksanakan pada:

1. Waktu: Perancangan alat ini dilakukan dari bulan Maret sampai dengan bulan Juni 2018.

2. Tempat: di Workshop Jurusan Teknik Mesin Otomotif, Politeknik Negeri Tanah Laut.

\section{Alat dan Bahan}

Alat dan bahan yang digunakan dalam pembuatan turbin angin adalah sebagai berikut:

\section{Alat}

1. Gerinda tangan (Hand grinding)

2. Meteran (Meter)

3. Tukul (Hammer)

4. Kunci kombinasi $12 \mathrm{~mm}$ (Combination lock $12 \mathrm{~mm}$ )

5. Kunci kombinasi $10 \mathrm{~mm}$ (Combination lock $10 \mathrm{~mm}$ )

6. Kunci kombinasi $19 \mathrm{~mm}$ (Combination lock $19 \mathrm{~mm}$ )

7. Kunci kombinasi $13 \mathrm{~mm}$ (Combination lock $13 \mathrm{~mm}$ )

8. Kunci kombinasi $17 \mathrm{~mm}$ (Combination lock $17 \mathrm{~mm}$ )

9. Kunci shok (Lock shock)

10. Amplas (Sandpaper)

11. Kikir (Miserli)

12. Bor tangan (Hand drill)

13. Bor duduk (Drill sitting)

14. Las listrik (Electrik welding)

15. Gerinda duduk (Grinding wheel)

\section{Bahan}

1. Kayu (Wood)

2. Besi has 3 diameter

3. Baut 12, 14, 17, dan $19 \mathrm{~mm}$

4. Elektroda 3,2 (Welding elektrodes)

5. Bantalan duduk (Bearing sitting)

6. Besi plat $3 \mathrm{~mm}$

\section{Prosedur Pengerjaan}

1. Mempersiapkan alat dan bahan

2. Mengukur kecepatan angin

3. Menentukan jumlah blade

4. Menentukan panjang dan ketebalan blade

5. Menentukan ukuran rotor hub

6. Menentukan panjang rotor

7. Melakukan perakitan/pemasangan semua komponen blade turbin angin

8. Melakukan pengukuran kecepatan poros blade

9. Melakukan pengambilan data hasil pengukuran kecepatan poros blade

10. Bersihkan, simpan alat dan bahan. 


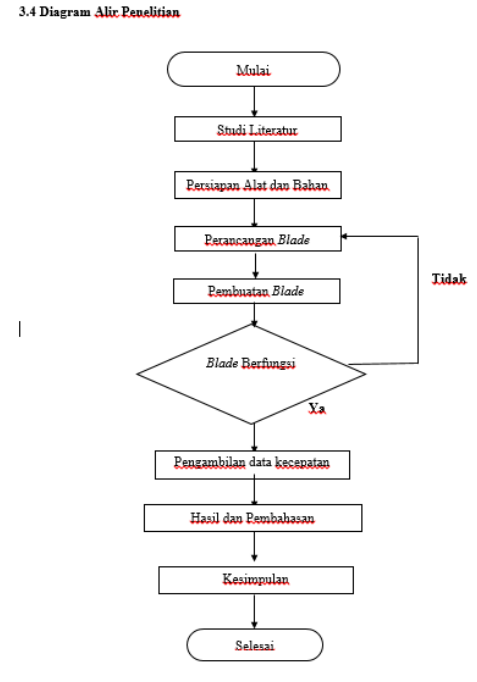

Gambar 2 Diagram alir penelitian

\section{HASIL DAN PEMBAHASAN}

\section{Perancangan Blade}

Luasan Blaade yang telah direncanakan dapat dihitung dengan menggunakan persamaan: $S=\frac{B \cdot a}{A}$

$$
\begin{aligned}
& \text { S = Solidity } \\
& \text { B = Jumlah blade } \\
& \alpha=\text { Luasan blade } \\
& \mathrm{A}=\text { Luasan tangkapan }
\end{aligned}
$$

angin

$$
\begin{aligned}
& \mathrm{B}=\text { Jumlah blade }\left(\mathrm{m}^{2)}\right) \\
& \mathrm{B}=3 \\
& \begin{aligned}
\alpha= & \text { Luasan blade }\left(\mathrm{m}^{2)}\right) \\
\alpha= & \mathrm{P} . \mathrm{L} \\
& \mathrm{P}=\text { Panjang blade }
\end{aligned}
\end{aligned}
$$

$$
\mathrm{L}=\text { Lebar blade }
$$

$\alpha=0,20.1,6$

$\left.\alpha=0,32 \mathrm{~m}^{2}\right)$

$\alpha=$ Luasan blade

Diketahui:

Diameter turbin $(\mathrm{m})=3,20 \mathrm{~m}$

Jari-jari turbin $=1,60 \mathrm{~m}$

$$
\begin{aligned}
& \pi=3,14 \\
& B=\text { jumlah blade } \\
& B=3
\end{aligned}
$$

$A=$ Luasan tangkapan angin

$A=\pi r^{2}$

Dimana $\mathrm{r}$ (yang digunakan) $=1,6 \mathrm{~m}^{2}$

$$
=3,14 .(1,60)^{2}=8,03 \mathrm{~m}^{2}
$$

$S=\frac{B \cdot \alpha}{\mathrm{A}}$
$S=$

$S=0,11$

Sedangkan jumlah massa yang melewati suatu tempat per unit waktu adalah:

Dimana:

$\dot{m}=$ Massa $(\mathrm{kg})$

$A=$ Luas Penampang $\left(\mathrm{m}^{2}\right)$

$v=$ Kecepatan Angin $(\mathrm{m} / \mathrm{s})$

$\rho=$ Kerapatan $\left(\mathrm{kg} / \mathrm{m}^{3}\right)$

$A=\mathrm{P}$. L

$\mathrm{P}=$ Panjang blade

$\mathrm{L}=$ Lebar blade

$A=0,2$. 1,6

$A=0,32 m^{2}$ )

$\mathrm{V}=$ Kecepatan $\operatorname{angin}(\mathrm{m} / \mathrm{s})$

$\mathrm{V}=15 \mathrm{~m} / \mathrm{s}$

$\rho=\operatorname{Kerapatan}\left(\mathrm{kg} / \mathrm{m}^{3}\right)$

$\rho=1,29 \mathrm{~kg} / \mathrm{m}^{3}$ )

$\dot{m}=A . \mathrm{V} . \rho$

$\dot{m}=0,32 \cdot 15.1,29$

$\dot{m}=6,19 \mathrm{~kg} / \mathrm{s}$

Dari perhitungan yang telah dilakukan didapat nilai solidity sebesar 0,11 , dengan nilai solidity tersebut maka blade dapat berfungsi dengan baik. Dilihat dari perhitungan di atas maka massa yang melewati suatu tempat sebesar $6,19 \mathrm{~kg} / \mathrm{s}$, nilai tersebut sudah cukup untuk memutar blade. Jika kecepatan angin lebih cepat maka massa yang melewati suatu tembat lebih besar dan pukulan massa yang memukul blade lebih besar, dari nilai massa udara yang melewati blade inilah yang membuat terjadi perbedaan kecepatan poros.

\section{Cara pembuatan blade turbin angin}

1. membuat kayu persegi panjang dengan ukuran panjang $160 \mathrm{~cm}$ dan lebar $20 \mathrm{~cm}$

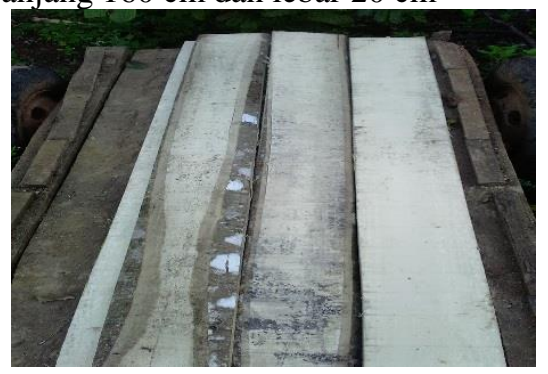

Gambar 3 Kayu Persegi panjang

2. Pembentukan kayu menjadi simetris agar tangkapan blade lebih optimal 


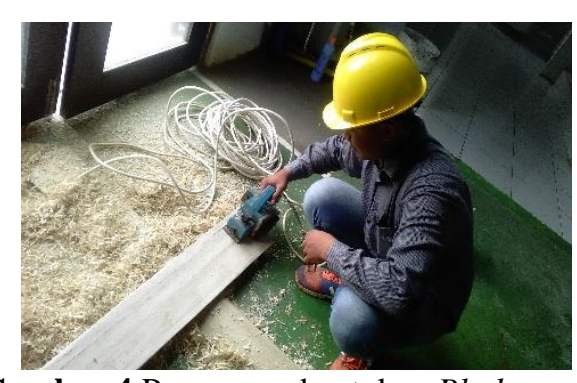

Gambar 4 Proses pembentukan Blade

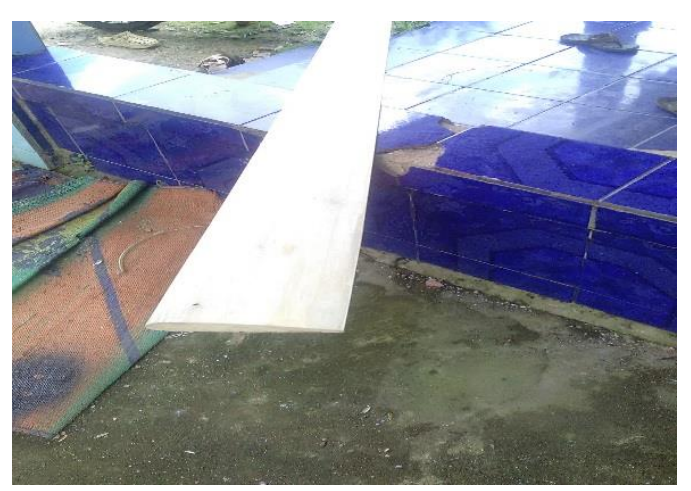

Gambar 5 Bentuk Blade simetris

3. Pembuatan penampang blade

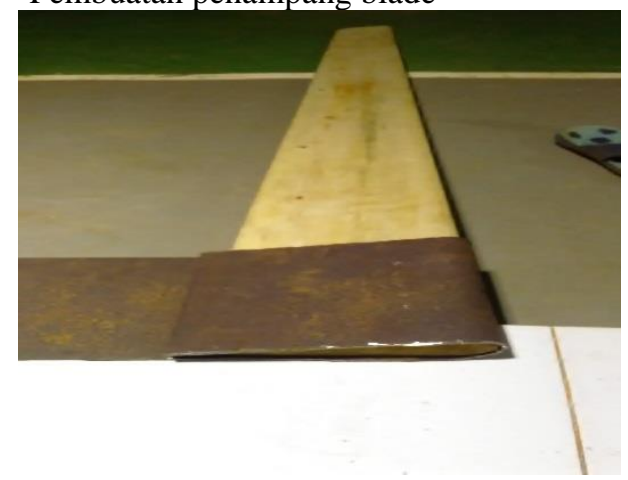

Gambar 6 Pembuatan penampang blade

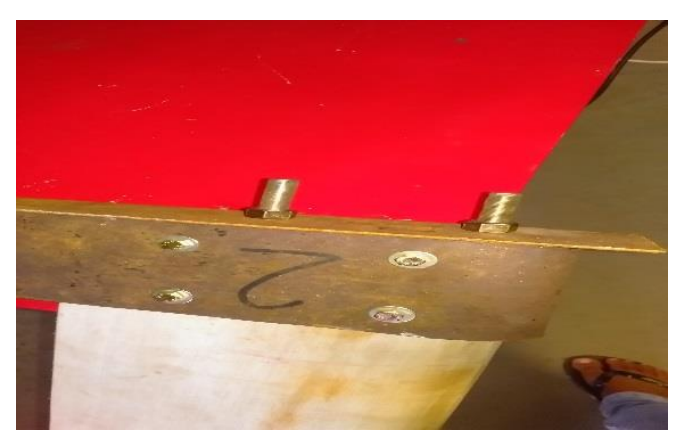

Gambar 7 Tutup penampang blade

4. Pengeleman blade menggunkan piber agar tidak keropos

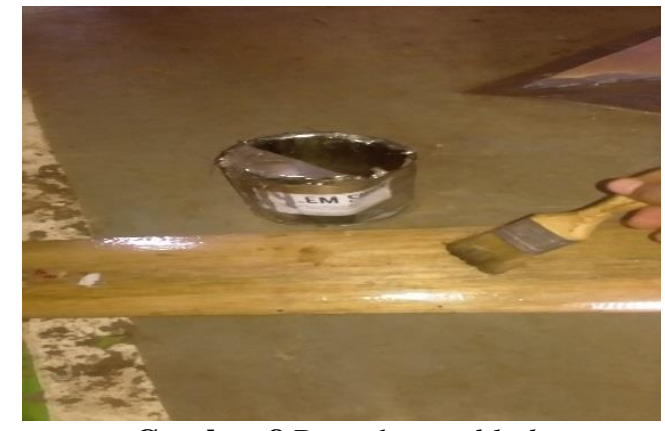

Gambar 8 Pengeleman blade

5. Pemasangan blade terhadap poros

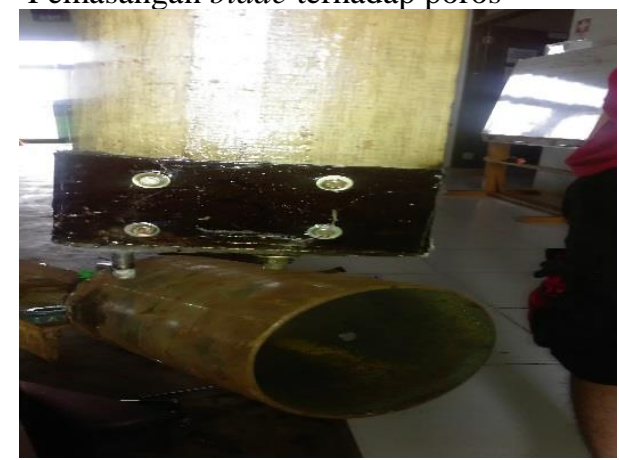

Gambar 9 Pemasangan blade

\section{Kecepatan poros}

Hasil penelitian dilakukan menggunakan Tachometer untuk mencatat kecepatan poros pada turbin angin. Hasil kecepatan poros tersebut dapat dilihat pada gambar 4.13 dan table 4.1.

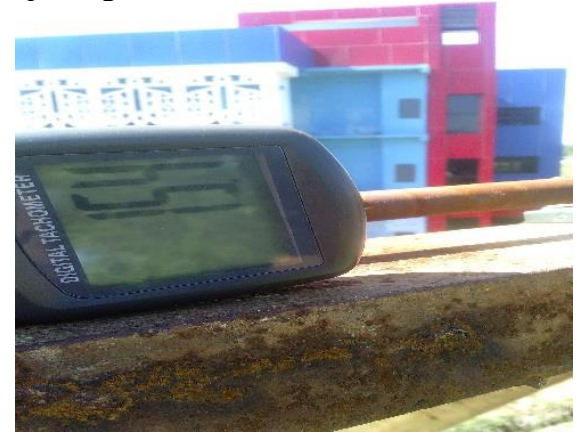

Gambar 10 Kecepatan poros

Dilihat dari data di atas maka kecepatan poros dalam 10 kali pengujian dari jam 13.00 sampai jam 14.30 maka kecepatan putaran poros paling cepat adalah $171 \mathrm{rpm}$ dengan kecepatan angin 18 $\mathrm{m} / \mathrm{s}$, sedangkan kecepatan poros paling rendah adalah $80 \mathrm{rpm}$ pada jam 13:30 dikarenakan kecepatan angin berkurang. 


\section{KESIMPULAN}

Kesimpulan yang dapat di ambil berdasarkan hasil optimasi dan pembahasan yang telah dilakukan adalah:

1. Perancangan blade dapat disimpulkan dengan perancangan blade tampak depan, tampak atas, dan tampang samping. Pembuatan blade adalah dengan pembentukan blade, pembuatan penampang blade, pengeleman, dan pemasangan blade ke poros.

2. Kecepatan putaran poros dalam 10 kali pengujian yang paling maksimal adalah 171 $\mathrm{rpm}$, dengan kecepatan angin $18 \mathrm{~m} / \mathrm{s}$.

\section{DAFTAR PUSTAKA}

[1] Yuni, 2002, Pemanfaatan Angin sebagai Pembangkit Listrik, Jakarta
[2] Daryanto, 2007. Kajian potensi angin untuk pembangkit listrik tenaga banyu. Balai PPTAGG-UPT-LAGG

[3] Soroyo, 2001, Analisis Teknis Sudu Kincir Angina Tipe Sudu Horizontal , Indralaya

[4] Martono, 2009, Karekteristik Dan Variabel Angin Permukaan Samudra Hindia, Bandung.

[5] Sumiati Ruzita, 2014 dkk, turbin angin pembangkit istrik untuk rumahan, Jakarta

[6] Firman Aryanto, 2013, Pengaruh Kecepatan Angin, Mataram.

[7] Suwoto Gatot, 2001, Karakteristik turbin angin poros Horozontal, Jakarta

[8] Amri khairul, 2014, Rancang bangun micro turbin angin pembangkit listrik untuk rumahan, Semarang

[9] Harrison, 2000, Rancangan awal dan analisis bentuk sudu turbin angin, Jakarta. 